Reprod. Nutr. Dévelop., 1988, 28 (1), 123-124.

\title{
Origine des protéines du contenu de rumen du veau préruminant
}

\author{
I. NUNES DO PRADO, R. TOULLEC, P. GUILLOTEAU, J.-P. BARLET $\left(^{*}\right)$ \\ Laboratoire du Jeune Ruminant, \\ I.N.R.A., 65, rue de Saint-Brieuc, 35042 Rennes Cedex, France. \\ (*) Laboratoire des Maladies métaboliques, \\ I.N.R.A., Theix, 63122 Ceyrat.
}

Summary. Rumen juice protein in the preruminant calf appears to be mainly of endogenous origin. When milk was poured into the rumen, its protein was slowly degraded since it was found in appreciable amount $16 \mathrm{~h}$ later.

Le but de ce travail a été d'estimer l'origine des protéines normalement présentes dans le rumen du veau préruminant et d'étudier le devenir des protéines du lait lorsqu'une partie de la ration est introduite dans cet organe.

Matériel et méthodes. Trois veaux, recevant 2 fois/j un lait de remplacement riche en poudre de lait écrémé, sont munis d'une canule du rumen. Ils sont soumis à 2 périodes de mesures de 3 semaines, pendant lesquelles la ration journalière est distribuée en totalité au seau (période témoin T) ou en partie $(25 \%)$ introduite dans le rumen, immédiatement après la buvée (période expérimentale E). Quatre échantillons moyens de jus de rumen sont constitués en réunissant des prélèvements effectués 2 fois par semaine avant le repas du matin (OT et $0 \mathrm{E}$ ) et $2 \mathrm{~h}$ après (2T et $2 \mathrm{E}$ ) pendant les périodes $\mathrm{T}$ (OT et $2 \mathrm{~T}$ ) et $\mathrm{E}$ (OE et 2E). Deux échantillons moyens de salive sont obtenus en mélangeant des prélèvements effectués à l'aide d'un cathéter réentrant placé dans le canal parotidien gauche, respectivement chez 4 veaux nourris au lait et consommant environ $100 \mathrm{~g}$ d'aliment concentré et $300 \mathrm{~g}$ de foin (123 prélèvements) et 4 jeunes bovins recevant exclusivement de l'aliment concentré et du foin (38 prélèvements). Pour tenter d'estimer l'origine des protéines, les compositions en acides aminés (AA) sont comparées entre elles et à celles des protéines alimentaires, endogènes ou microbiennes en calculant la distance du $\chi^{2}$ (Guilloteau et al., 1983).

Résultats et discussion. La composition en AA de la salive variant peu avec le régime alimentaire, seules les valeurs moyennes sont rapportées (tabl. 1). Pendant la période $T$, les protéines du jus de rumen collecté avant le repas (0T) semblent 
TABL. 1. - Composition en acides aminés (AA) de l'aliment, de la salive et des jus prélevés dans le rumen avant le repas (0T et $0 \mathrm{E})$ ou 2 h après (2T et $2 \mathrm{E})$, pendant les périodes oú le lait est distribué entièrement au seau (OT et $2 \mathrm{~T}$ ) ou partiel/ement (25\%) introduit dans le rumen (OE et $2 \mathrm{E}$ ).

\begin{tabular}{|c|c|c|c|c|c|c|}
\hline \multirow{2}{*}{ Acide aminé } & \multirow{2}{*}{ Aliment } & \multirow{2}{*}{ Salive } & \multicolumn{4}{|c|}{ Jus de rumen } \\
\hline & & & OT & $2 \mathrm{~T}$ & $\mathrm{OE}$ & $2 E$ \\
\hline A. aspartique & 8,31 & 11,51 & 9,83 & 9,73 & 9,20 & 9,65 \\
\hline Thréonine & 4,83 & 4,82 & 4,74 & 4,77 & 5,10 & 5,49 \\
\hline Sérine & 5,25 & 5,19 & 6,27 & 7,79 & 5,72 & 5,43 \\
\hline A. glutamique & 20,22 & 14,36 & 16,05 & 10,93 & 17,92 & 19,16 \\
\hline Proline & 9,26 & 6,53 & 4,09 & 4,61 & 6,56 & 8,37 \\
\hline Glycine & 1,96 & 4,38 & 6,15 & 5,38 & 4,45 & 2,72 \\
\hline Alanine & 3,19 & 4,59 & 5,31 & 4,99 & 4,81 & 4,13 \\
\hline Valine & 6,38 & 6,36 & 6,04 & 7,06 & 6,04 & 5,75 \\
\hline Cystine & 0,83 & 1,96 & 2,07 & 2,77 & 1,46 & 1,19 \\
\hline Méthionine & 2,76 & 0,90 & 1,40 & 2,03 & 1,71 & 2,06 \\
\hline Isoleucine & 5,10 & 5,30 & 4,85 & 5,21 & 4,74 & 5,27 \\
\hline Leucine & 9,40 & 8,22 & 9,43 & 9,77 & 9,16 & 9.77 \\
\hline Tyrosine & 4,78 & 4,20 & 3,97 & 4,46 & 4,53 & 4,08 \\
\hline Phénylalanine & 4,71 & 5,38 & 4,64 & 5,16 & 4,58 & 4,46 \\
\hline Lysine & 7,12 & 6,81 & 6,16 & 6,37 & 6,57 & 6,49 \\
\hline Histidine & 2,41 & 3,16 & 2,43 & 2,50 & 2,34 & 2,23 \\
\hline Arginine & 3,49 & 6,37 & 6,57 & 6,47 & 5,11 & 3,75 \\
\hline NAA dosés $\% N$ total & 85,1 & 22,2 & 87,9 & 70,8 & 88,8 & 80,4 \\
\hline
\end{tabular}

être apportées principalement par les desquamations et la salive car leur composition est voisine de celle d'un mélange théorique comprenant $60 \%$ de protéines de tissu intestinal de porc (Pion et Fauconneau, 1968) et $40 \%$ de protéines de salive $\left(\chi^{2}=34\right.$, au lieu de 254 par rapport à l'aliment). II n'y aurait que peu de protéines microbiennes dans OT car l'introduction de $10 \%$ de protéines de bactéries de rumen (Pion et Fauconneau, 1968) dans le mélange défini ci-dessus amène le $\chi^{2}$ à 36 . La composition en $\mathrm{AA}$ de $2 \mathrm{~T}$ reste très différente de celle de l'aliment $\left(\chi^{2}=309\right)$. Elle se distingue de celle de OT par une teneur en acide glutamique inférieure de $32 \%\left(\chi^{2}=55\right)$ et ressemble plus à celle du suc pancréatique de veau $\left(\chi^{2}=34\right)$ (Guilloteau et al., 1983). Cela pourrait s'expliquer par une composition en AA différente des sécrétions salivaires stimulées par le repas, par rapport à celle de la salive parotidienne. Pendant la période $E$, la composition en $A A$ des jus de rumen (OE et $2 E$ ) se rapproche de celle de l'aliment, surtout après le repas $\left(\chi^{2}\right.$ de 93 et 26). Un mélange comprenant $58 \%$ de protéines de $0 \mathrm{~T}$ et $42 \%$ de protéines alimentaires aurait une composition pratiquement identique à celle de $0 \mathrm{E}\left(\chi^{2}=3\right)$. Les valeurs correspondantes qui permettraient de minimiser la valeur du $\chi^{2}$ par rapport à $2 \mathrm{E}$ sont de 23 et $77 \%$ $\left(\chi^{2}=10\right)$.

En conclusion, chez le veau préruminant, les protéines du jus de rumen sont normalement d'origine endogène. Lorsque du lait est introduit dans le rumen, ses protéines ne sont éliminées que très lentement puisqu'elles constituent encore environ $40 \%$ de celles du contenu $16 \mathrm{~h}$ plus tard, alors que le lactose disparaît en $6 \mathrm{~h}$ (Nunes do Prado et al., 1987).

Guilloteau P., Sauvant D., Patureau-Mirand P., 1983. Ann. Nutr. Métab., 27, 457-459.

Nunes do Prado I., Toullec R., Manis Y., Guilloteau P., 1987. Reprod. Nutr. Dévelop., 27, $253-254$. Pion R., Fauconneau G., 1968. In /sotope studies on the nitrogen chain, 3-59, 1.A.E.A., Vienne. 